\title{
A FORMAÇÃO ACADÊMICA DO ENGENHEIRO: PRODUTO DE UMA ATIVIDADE COLETIVA
}

\author{
LA FORMACIÓN ACADÉMICA DEL INGENIERO: PRODUCTO DE UNA \\ ACTIVIDAD COLECTIVA
}

\author{
THE ACADEMIC EDUCATION OF THE ENGINEER: A PRODUCT OF A \\ COLLECTIVE ACTIVITY
}

\author{
Isabel Koltermann BATTISTI ${ }^{1}$ \\ Cátia Maria NEHRING ${ }^{2}$
}

RESUMO: O ensino é uma forma universal institucionalizada de transmitir às novas gerações saberes produzidos nas experiências sociais. Nesse contexto, a presente produção constitui-se a partir de uma investigação que visa discutir acerca da formação acadêmica do engenheiro como produto de uma atividade coletiva. Este é delimitado a partir da problemática: Quais elementos caracterizam a necessidade, o objeto e o motivo como componentes estruturadores da atividade Formação do engenheiro? Quais entendimentos podem ser produzidos, considerando a formação do engenheiro, no âmbito do ensino, como produto de uma atividade coletiva? As análises constituem-se a partir de referenciais teóricos fundamentados na perspectiva histórico-cultural, com enfoque especial à teoria da atividade, e consideram excertos do Projeto Pedagógico de cursos de Engenharia de uma universidade. O estudo desenvolvido permitiu indicar que a necessidade de formar um engenheiro se torna satisfeita na atividade coletiva, o que está intrinsecamente relacionado às ações individuais de cada professor envolvido.

PALAVRAS-CHAVE: Teoria da atividade. Abordagem histórico-cultural. Ensino. necessidade, objeto e motivo.

RESUMEN: La enseñanza es una forma universal institucionalizada de transmitir a las nuevas generaciones saberes producidos en las experiencias sociales. En este contexto, la presente producción se constituye a partir de una investigación que busca discutir acerca de la formación académica del ingeniero como producto de una actividad colectiva. Este es delimitado a partir de la problemática: ¿Qué elementos caracterizan la necesidad, el objeto y el motivo como componentes estructurados de la actividad Formación del ingeniero? ¿Qué entendimientos pueden ser producidos, considerando la formación del ingeniero, en el ámbito de la enseñanza, como producto de una actividad colectiva? Los análisis se constituyen a partir de referenciales teóricos fundamentados en la perspectiva histórico cultural, con enfoque especial a la teoría de la actividad, y consideran extractos del Proyecto Pedagógico de cursos

\footnotetext{
${ }^{1}$ Universidade Regional do Noroeste do Estado do Rio Grande do Sul (UNIJUI), Ijuí - RS - Brasil. Professor. Departamento de Ciências Exatas e Engenharias. Grupo de Estudos em Educação Matemática - (GEEM). Doutora. ORCID: <http://orcid.org/0000-0002-0939-3483>.E-mail: isabel.battisti@unijui.edu.br

${ }^{2}$ Universidade Regional do Noroeste do Estado do Rio Grande do Sul (UNIJUI), Ijuí - RS - Brasil. Professor. Departamento de Ciências Exatas e Engenharias. Grupo de Estudos em Educação Matemática - (GEEM). Doutora. ORCID <http://orcid.org/0000-0001-5372-4107>. E-mail: catia@unijui.edu.br
} 
de Ingeniería de una universidad. El estudio desarrollado permitió indicar que la necesidad de formar un ingeniero se vuelve satisfecha en la actividad colectiva, lo que está intrínsecamente relacionado con las acciones individuales de cada profesor involucrado.

PALABRAS CLAVE: Teoría de la Actividad. Enfoque histórico cultural. Educación. Necesidad, objeto y motivo.

ABSTRACT: Teaching is a universal institutionalized way of transmitting the knowledge produced in social experiences to the new generations. In this context, this research is constituted from an investigation that aims to discuss about the academic formation of the engineer as the product of a collective activity. The following issues delimit it: which elements characterize the necessity, the object, and the reason as structuring components of the engineer training activity? What understandings can be produced, considering the engineer training, in the scope of teaching as the product of a collective activity? The analyzes arise from theoretical references based on the historical-cultural perspective, with special focus on the Activity Theory, and considering excerpts from the Pedagogical Project of Engineering courses of a university. The study allows to indicate that the need to form an engineer becomes satisfied in the collective activity, which is intrinsically related to the individual actions of each teacher involved.

KEYWORDS: Activity Theory. Historical-cultural approach. Teaching. Need, object and reason.

\section{Introdução}

A formação profissional do engenheiro não acontece de forma natural, mas a partir de um ensino intencional, formal e acadêmico. O ensino é uma forma universal institucionalizada de transmitir às novas gerações os saberes produzidos nas experiências sociais. A sociedade criou um meio para atender às necessidades geradas intencionalmente no e do seu próprio desenvolvimento. "Essa forma de agir para satisfazer necessidades é denominada de trabalho, pois, além de satisfazer suas necessidades, os homens produzem os meios para isso.” (MOURA; SFORNI; ARAÚJO, 2011, p. 41).

Vigotski (2001) compreende as características do homem a partir da origem e do desenvolvimento da espécie humana. Considera o surgimento do trabalho e a formação da sociedade humana como processo básico que marca o homem como espécie diferenciada. A necessidade da busca pela sobrevivência institui o trabalho como uma ação coletiva de um grupo humano. Para Vigotski (2001), o trabalho, pela ação transformadora do homem sobre a natureza, une homem e natureza, e é no trabalho que se organizam a atividade coletiva e a 
criação e utilização de instrumentos ${ }^{3}$. Para Leontiev (1977), a transição do homem para a vida em sociedade fez com que surgissem, historicamente, processos ou ações em atividade direcionada, como é o caso do ensino.

O ensino formal configura-se como um meio organizado pela sociedade para satisfazer a necessidade das novas gerações de apropriar-se dos saberes já produzidos. Tal entendimento possibilita indicar que o trabalho, como uma atividade humana intencional, gerou tal necessidade e que, por meio do trabalho, o ensino é realizado pelo professor no exercício de sua atividade profissional, a qual faz parte de uma organização social e coletiva e a ela está integrada. O ensino, como produto de uma atividade física e mental, dessa forma, pode ser considerado uma objetivação do trabalho do professor.

Diante do exposto, a presente produção constitui-se a partir de uma investigação que visa discutir acerca da formação acadêmica, no caso do engenheiro, como produto de uma atividade de ensino que se dá no âmbito da coletividade. Esta é delimitada a partir da problemática: Quais elementos caracterizam a necessidade, o objeto e o motivo como componentes estruturadores da atividade Formação do engenheiro? Quais entendimentos podem ser produzidos, considerando a formação do engenheiro, no âmbito do ensino, como produto de uma atividade coletiva?

\section{Caminho metodológico}

A presente produção é um recorte de uma pesquisa que se deu em nível de doutoramento (BATTISTI, 2016) e que teve como objetivo: analisar, com e a partir de ações de uma disciplina de cursos de Engenharia, a estruturação/articulação/proposição da mediação na constituição de processos que visam à significação do conceito vetor e operações de vetores pelo acadêmico. A pesquisa desenvolveu-se a partir de ações de uma disciplina de cursos de Engenharia. A escolha se fez por ser este o espaço institucional responsável pela formação acadêmica profissional de sujeitos que necessitam apropriar-se de conceitos científicos para atenderem ao perfil do egresso indicado pelas Diretrizes Curriculares dos Cursos de Engenharias - DCNs ${ }^{4}$ (BRASIL, 2002). Na pesquisa de âmbito maior intencionava-se tratar do professor em atividade de ensino, considerando sua necessidade: ensinar. Contudo, ao imergirmos nas análises,

${ }^{3} \mathrm{O}$ instrumento "[...] é um elemento interposto entre o trabalhador e o objeto de seu trabalho" (OLIVEIRA, 2004, p. 29); é, assim, um objeto social e mediador da relação entre o indivíduo e o mundo.

${ }^{4}$ Documento que define "[...] os princípios, fundamentos, condições e procedimentos da formação de engenheiros, estabelecidas pela Câmara de Educação Superior do Conselho Nacional de Educação, para aplicação em âmbito nacional na organização, desenvolvimento e avaliação dos projetos pedagógicos dos Cursos de Graduação em Engenharia das Instituições do Sistema de Ensino Superior.” (BRASIL, 2002, p. 1). 
deparamo-nos com outro processo vivenciado que antecede a própria inserção nas aulas de uma determinada disciplina. Houve a necessidade da produção de entendimentos que considerassem o professor imerso nos cursos considerados. É nesse sentido que as tratativas apresentadas no presente recorte constituem-se.

Para tanto, fez-se necessário, no desenvolvimento da pesquisa, a articulação de dois movimentos metodológicos, um empírico e outro teórico. As condições de análise constituíramse e foram ampliadas a partir de referenciais teóricos fundamentados na perspectiva históricocultural, com enfoque especial à teoria da atividade e à Atividade Orientadora do Ensino, que possuem como referência Lev Semenovich Vigotski, Alexis Nikolaevich Leontiev, Alexander Romanovich Luria e Manoel Oriosvaldo de Moura, além de estudiosos de suas proposições.

No recorte aqui delineado, considera-se dados empíricos produzidos na pesquisa, de forma especial, excertos do Projeto Pedagógico de Curso - PPC de três cursos de Engenharia (Civil - EC; Elétrica- EE; e Mecânica- EM), da universidade em que a pesquisa de âmbito maior foi desenvolvida.

As análises empreendidas visam à produção de um conhecimento novo, no caso, relacionado à formação do engenheiro, entendendo está como produto de uma atividade coletiva, o que demanda perceber, no movimento da interdependência ${ }^{5}$ e da fluência ${ }^{6}$, a ideia de totalidade do fenômeno. Isso significa, de acordo com Kopnin (1978), considerar o concreto como ponto de partida e de chegada do conhecimento, cujo percurso demanda um processo de abstração. Kopnin afirma que é a abstração que permite perceber o conteúdo real do objeto, no caso, a formação do engenheiro. Segundo o referido autor, “[...] a tarefa da abstração não é separar um dos outros os indícios sensorialmente perceptíveis, mas através deles descobrir novos aspectos no objeto que traduzam as relações de essência" (KOPNIN, 1978, p. 161) atrás do sensorialmente perceptível, descobrir propriedades, aspectos, indícios e relações que constituem a essência do objeto.

No entanto, como encontrar, no movimento da interdependência e da fluência, os fatos ou os próprios objetos de estudo? Para tanto, reportamo-nos a Caraça quando propõe para tal problema o conceito de isolado. Afirma:

$\mathrm{Na}$ impossibilidade de abraçar, num só golpe, a totalidade do universo, o observador recorta, destaca, dessa totalidade, um conjunto de seres e fatos, abstraindo de todos os outros que com eles estão relacionados.

5 A realidade é um organismo vivo cujos compartimentos comunicam e participam uns da vida dos outros, relacionam-se intrinsecamente entre si. (CARAÇA, 1998).

${ }^{6} \mathrm{O}$ mundo está em permanente evolução, todas as coisas, a todo momento, se transformam, tudo devém, tudo é, a todo momento, uma coisa nova. (CARAÇA, 1998). 
A um tal conjunto daremos o nome de isolado; um isolado é, portanto, uma secção da realidade, nela recortada arbitrariamente. (CARAÇA, 1998, p. 112, grifo do autor).

O conceito de isolado, nessa abordagem, significa o integrante do todo, como uma secção da realidade que conserva "[...] todos os fatores que, ao se interdependerem, têm influência marcante no fenômeno a estudar." (MOURA, 2004, p. 267). O isolado como uma secção afasta uma parte do resto da realidade; o seu uso comporta, assim, certa margem de erro que influencia o estudo. Cabe, então, ao pesquisador selecionar isolados que conservem os fatores dominantes, ou seja, aqueles cuja ação de interdependência influem no fenômeno a estudar.

De acordo com Araújo (2003), os isolados mostram-se como recursos metodológicos para a abstração autêntica e permitem a compreensão do objeto na dimensão do concretamente pensado. Este entendimento “[...] legitima que o estudo de um conjunto determinado de isolados sirva de referência" (ARAÚJO, 2003, p. 58). A autora ratifica e amplia esta ideia ao trazer Moura quando este diz que o isolado "[...] é assumido como metodologia de análise, como uma regularidade do pensamento ao atuar sobre a complexidade da realidade e não com uma concepção desta." (MOURA, 2000, p. 81).

A análise a partir de isolados implica recortes do todo, considerando as relações de interdependência e de fluência, de maneira que cada parte está no todo e o todo está em cada parte.

$\mathrm{Na}$ investigação aqui apresentada, toma-se para estudo parte do fenômeno formação do engenheiro, considera-se essa formação, no âmbito do ensino, como produto de uma atividade coletiva. O referido fenômeno é consoante com o problema central da pesquisa. Assume-se, assim, como isolados os componentes, que de acordo com Leontiev (s/d), são estruturadores da atividade: necessidade, objeto e motivo. Elementos destes isolados, no nosso entendimento, apresentam singularidades, mas também uma dinâmica relacional entre si, não de uma forma hierárquica, mas dialética, tanto do ponto de vista temporal quanto qualitativo. Nesse sentido, de acordo com Araújo (2003), os isolados são considerados como princípio da metodologia dialética, em que se toma uma unidade que faz parte do todo para análise.

\section{Formação acadêmica do engenheiro como produto de uma atividade coletiva: análises no âmbito do ensino}

Em Instituições de Ensino, os cursos propostos em nível superior visam a uma formação profissional. E, assim, como a própria instituição, são regidos e normatizados por uma 
organização social criada na e pela sociedade, visando a atender às necessidades que emergiram no e do seu próprio desenvolvimento. Ao ser formado na instituição de Educação Superior, espera-se que o acadêmico apresente condições básicas para o exercício profissional e habilidades intelectuais e emocionais fundamentais para continuar aprendendo por toda a vida, mas também que tenha as condições de exercício da cidadania que balizem a sua formação.

O perfil do formando egresso/profissional engenheiro é apresentado pelas DCNs dos cursos de Engenharia, indica que este deve ter uma

[...] formação generalista, humanista, crítica e reflexiva, capacitado a absorver e desenvolver novas tecnologias, estimulando a sua atuação crítica e criativa na identificação e resolução de problemas, considerando seus aspectos políticos, econômicos, sociais, ambientais e culturais, com visão ética e humanística, em atendimento às demandas da sociedade (BRASIL, 2002, p. $1)$.

Os objetivos da formação do engenheiro são apresentados no Art. $4^{\circ}$ das DCNs de Engenharia, visando a dotar estes profissionais de competências e habilidades gerais, dentre as quais, destacamos:

I - aplicar conhecimentos matemáticos, científicos, tecnológicos e instrumentais à engenharia; II - projetar e conduzir experimentos e interpretar resultados; [...] V - identificar, formular e resolver problemas de engenharia; VI - desenvolver e/ou utilizar novas ferramentas e técnicas; [...] VIII comunicar-se eficientemente nas formas escrita, oral e gráfica; [...] XI - avaliar o impacto das atividades da engenharia no contexto social e ambiental; XII avaliar a viabilidade econômica de projetos de engenharia; XIII - assumir a postura de permanente busca de atualização profissional (BRASIL, 2002, p. 2).

As turmas envolvidas no M1 da pesquisa eram compostas por acadêmicos de diferentes cursos de Engenharia - Engenharia Civil - EC, Mecânica - EM, Elétrica - EE e Química - EQ e de Ciência da Computação - CC. A grande maioria dos acadêmicos pertencia aos cursos de EC, EE e EM. Os objetivos gerais de tais cursos são explicitados nos seus Projeto Pedagógico de Curso - PPC e apresentados no Quadro 1. 
Quadro 1 - Objetivos gerais dos cursos de EC, EE e EM

\begin{tabular}{|l|l|}
\hline Curso & \multicolumn{1}{c|}{ Objetivos Gerais } \\
\hline EC & $\begin{array}{l}\text { A formação generalista proposta pelo curso de Engenharia Civil da XXXX busca habilitar } \\
\text { Engenheiros Civis para que exerçam a profissão de forma qualificada e com senso crítico } \\
\text { e de cidadania, praticando as seguintes atitudes, durante sua vida profissional: [i] } \\
\text { Compromisso com a ética profissional; [ii] Responsabilidade social, política e ambiental; } \\
\text { [iii] Espírito empreendedor: postura pró-ativa e inovadora; [iv] Compreensão da necessidade } \\
\text { de busca permanente de atualização profissional. }\end{array}$ \\
\hline EE & $\begin{array}{l}\text { A formação generalista proposta pelo curso de Engenharia Elétrica da XXXX } \\
\text { busca habilitar Engenheiros Eletricistas para que exerçam a profissão de forma } \\
\text { qualificada e com senso crítico e de cidadania, praticando as seguintes atitudes, durante } \\
\text { sua vida profissional: [i] Compromisso com a ética profissional; [ii] Responsabilidade } \\
\text { social, política e ambiental; [iii] Espírito empreendedor: postura pró-ativa e inovadora; } \\
\text { [iv] Compreensão da necessidade de busca permanente de atualização profissional. }\end{array}$ \\
\hline EM & $\begin{array}{l}\text { O curso de Engenharia Mecânica tem por objetivo geral a formação de profissionais } \\
\text { qualificados com uma sólida formação técnica, científica e profissional, além de um } \\
\text { senso de constante atualização profissional, que o capacite a absorver e desenvolver novas } \\
\text { tecnologias, estimulando a sua atuação crítica e criativa na identificação e resolução de } \\
\text { problemas, considerando seus aspectos políticos, econômicos, sociais, ambientais e e } \\
\text { culturais, com uma visão ética e humanista, em atendimento às demandas da sociedade. }\end{array}$ \\
\hline
\end{tabular}

Fonte: M1. PPC - EC (Versão 2013); PPC - EE (Versão 2014); PPC - EM (Versão 2014). [Grifo nosso].

Os objetivos gerais propostos para os cursos de EC e de EE mencionam uma formação generalista, que é também indicada no PPC do curso de EM ao apresentar os fundamentos norteadores para a concepção do curso. Os três cursos, nos objetivos apresentados no Quadro 1, consideram uma formação qualificada, atualização profissional e aspectos políticos, econômicos, sociais, ambientais e culturais, com uma visão responsável, ética e humanista da profissão pelo acadêmico. A análise dos referidos objetivos aponta que os cursos EC e EE propõem, ainda, de forma explícita, uma postura pró-ativa e inovadora no exercício profissional; já o curso EM indica o estímulo à atuação crítica e criativa na identificação e resolução de problemas, visando ao atendimento das demandas da sociedade.

No Quadro 2, apresenta-se aspectos do perfil do egresso proposto nos PPCs dos referidos cursos. 
Quadro 2 - Excertos do PPC que revelam elementos relacionados ao perfil do egresso dos cursos de EC, EE e EM da IES

\begin{tabular}{|c|c|}
\hline Curso & Perfil do egresso - excertos do PPC \\
\hline EC & $\begin{array}{l}\text { Quanto ao perfil, o profissional a ser formado deverá estar apto a responder quantitativa e } \\
\text { qualitativamente aos anseios de desenvolvimento da sociedade. } \\
\text { Deverá ter uma sólida formação técnico-científica e profissional geral que o capacite a } \\
\text { absorver e desenvolver novas tecnologias, estimulando a sua atuação crítica, criativa, } \\
\text { inovadora e empreendedora na identificação e resolução de problemas, considerando seus } \\
\text { aspectos político-econômicos, sociais, ambientais e culturais, com visão ética e humanística, } \\
\text { em atendimento às demandas da sociedade. } \\
\text { Em decorrência da formação recebida, o profissional estará habilitado a aplicar o método } \\
\text { científico para a análise e solução de problemas pertinentes a sua área de atuação. }\end{array}$ \\
\hline $\mathbf{E E}$ & $\begin{array}{l}\text { Quanto ao perfil, o profissional a ser formado deverá estar apto a responder quantitativa e } \\
\text { qualitativamente aos anseios de desenvolvimento da sociedade. } \\
\text { Deverá ter uma sólida formação técnico-científica e profissional geral que o capacite a } \\
\text { absorver e desenvolver novas tecnologias, estimulando a sua atuação crítica, criativa e } \\
\text { inovadora na identificação e resolução de problemas, considerando seus aspectos político- } \\
\text { econômicos, sociais, ambientais e culturais, com visão ética e humanística, em atendimento } \\
\text { às demandas da sociedade. } \\
\text { Em decorrência da formação recebida, o profissional estará habilitado a aplicar o } \\
\text { método científico para a análise e solução de problemas pertinentes a sua área de atuação. }\end{array}$ \\
\hline EM & $\begin{array}{l}\text { O perfil enuncia e detalha as exigências que se fazem a um engenheiro mecânico } \\
\text { satisfatoriamente preparado para o exercício de sua profissão, em termos de: } \\
\text { conhecimentos gerais e específicos, de habilidades, competências e de atitudes. } \\
\text { [...] } \\
\text { A partir desse diagnóstico definiu o perfil do egresso do curso de Engenharia Mecânica da } \\
\text { xxx } \\
\text { - Postura crítico-reflexiva, de análise contextualizada frente à realidade; } \\
\text { - Flexibilidade e sensibilidade para conviver e adaptar-se às mudanças; } \\
\text { - Disposição para trabalho em equipe; } \\
\text { - Iniciativa para desenvolver, propor, implantar e divulgar novos conhecimentos, } \\
\text { tecnologias, serviços e produtos; } \\
\text { - Postura proativa e empreendedora frente às tendências decorrentes da dinâmica evolutiva } \\
\text { da sociedade; } \\
\text { - Atitude ética e responsável durante o exercício profissional; } \\
\text { - Aprender de forma autônoma e contínua; } \\
\text { - Atuar inter / multi / transdisciplinarmente; } \\
\text { - Comprometer-se com a preservação da biodiversidade no ambiente natural e construído; } \\
\text { com sustentabilidade e melhoria da qualidade da vida; } \\
\text { - Gerenciar processos participativos de organização pública e/ou privada e/ou incluir-se } \\
\text { neles; } \\
\text { - Buscar maturidade, sensibilidade e equilíbrio ao agir profissionalmente. }\end{array}$ \\
\hline
\end{tabular}

Fonte: PPC - EC (Versão 2013); PPC - EE (Versão 2014); PPC - EM (Versão 2014). [Grifo nosso]

A ideia de uma sólida formação técnico-científica e profissional perpassa os conhecimentos gerais e específicos, de habilidades, competências e de atitudes que possibilitem ao acadêmico uma atuação crítica, criativa e inovadora na identificação e resolução de problemas. Considerando-se aspectos político-econômicos, sociais, ambientais e culturais, com 
visão ética e humanística, em atendimento às demandas da sociedade, fundamenta-se o perfil do egresso dos referidos cursos.

\section{Componentes estruturadores da atividade formação do engenheiro: necessidade, objeto e motivo}

Diante do revelado pelo PPC dos cursos em questão, há, explicitamente, um produto almejado: a formação de um profissional levando em conta os objetivos do curso e o perfil do egresso apresentados nos referidos documentos. A Instituição de Educação Superior e os sujeitos envolvidos nesse processo têm uma necessidade: formar um engenheiro com tal perfil.

Essa necessidade, embasada em proposições apresentadas por Leontiev (1985), é satisfeita pela partilha do produto da atividade total que cada um recebe nas relações sociais que surgem no processo de trabalho. A necessidade de formar um engenheiro torna-se satisfeita na atividade coletiva, intrinsecamente relacionada às ações individuais.

A prática profissional do professor "[...] depende de decisões individuais, mas rege-se por normas coletivas adaptadas por outros professores e por regulações organizacionais" (SACRISTÁN, 1991, p. 71). O trabalho do professor está inserido num coletivo, e essa consciência é essencial na organização de um ensino que visa à formação profissional de um sujeito em nível superior. O professor, a partir da especificidade em que atua, deve considerar o curso de formação, pois este tem um objetivo social de integração dos sujeitos em uma determinada comunidade, o que lhes permite tomar parte no conjunto de saberes que constituem as práticas sociais e culturais do curso em questão, no caso, de Engenharia. A formação do engenheiro é um produto. Esse produto corresponde diretamente às necessidades dos participantes do processo - no caso do ensino, os professores das diferentes disciplinas que integram o programa curricular do referido curso. É este produto, a formação do engenheiro, que estimula a atividade de professores trabalhar juntos, o que caracteriza a atividade coletiva.

A atividade, de acordo com Leontiev (s/d), é estruturada pelos componentes: necessidade, objeto e motivo. No contexto considerado, o professor de cada disciplina tem uma necessidade: contribuir na formação do engenheiro; essa necessidade pode ser satisfeita no ensino dos conceitos da disciplina que ele ministra, o que se configura como objeto da atividade. O professor encontra-se motivado, ou seja, há motivo para o ensino de conceitos específicos da disciplina em que atua quando sente a necessidade de contribuir na formação do acadêmico no caso, do engenheiro - e na medida em que idealiza um objeto que possa satisfazer a referida necessidade. De acordo com Leontiev (s/d), a necessidade encontra sua determinação no objeto, 
o qual se torna o motivo da atividade, aquilo que a estimula. Portanto, propõem-se objetivos parciais advindos de objetivos gerais, que consideram o que poderá fazer para satisfazer tal necessidade, e estes se materializam nas ações. As ações apresentam aspectos que compreendem a intencionalidade do professor e também a forma como elas se realizam; dependem, assim, de condições concretas para efetivarem-se e atendem ao aspecto operacional. Nesse sentido, cada ação apresenta um conjunto de operações que dependem das condições de execução de cada ação. No caso do ensino, as operações podem referir-se aos procedimentos que o professor realizará para alcançar os objetivos propostos.

Os elementos atividade, ações e operações constituem um sistema cuja estrutura pode mostrar-se em dois níveis. A Figura 1 apresenta um esquema adaptado a partir do apresentado por Garnier, Bednarz e Ulanovskaya (1996), o qual mostra a estrutura em dois níveis da atividade.

Figura 1 - Estrutura em dois níveis da atividade

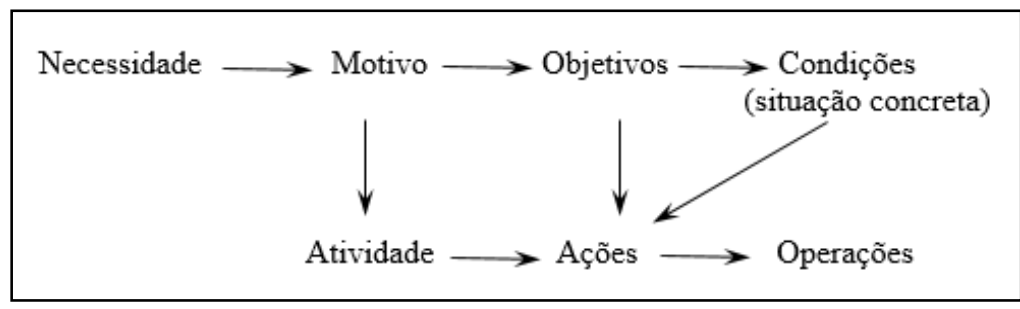

Fonte: Adaptado de Garnier, Bednarz e Ulanovskaya (1996, p. 13)

A estrutura da atividade proposta por Leontiev (s/d) também pode ser analisada a partir de seus níveis hierárquicos. Essa estrutura hierárquica da atividade apresentada por Leontiev foi sistematizada por Daniels (2003) na forma de uma representação triangular, como mostra a Figura 2.

Figura 2 - Representação gráfica da estrutura da atividade elaborada por Leontiev

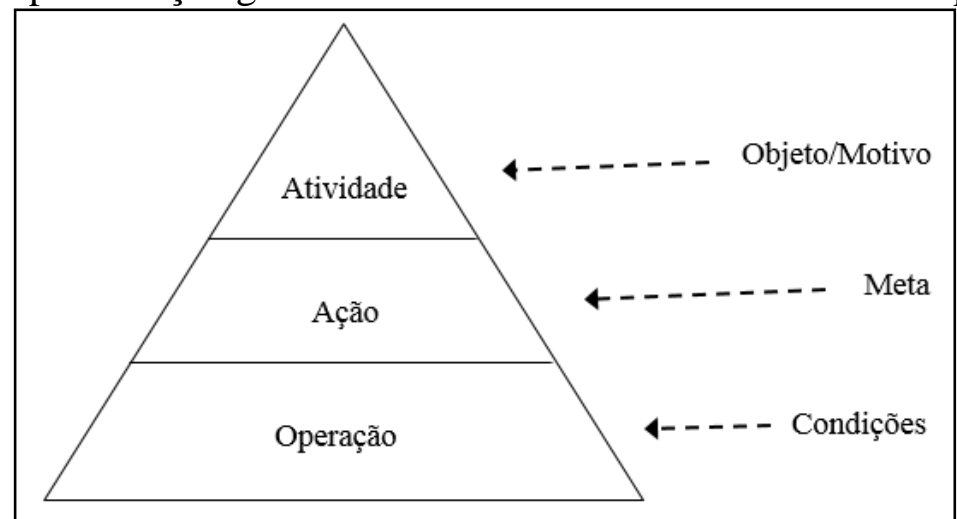

Fonte: Daniels (2003, p. 116) 
Na representação apresentada na Figura 2, Daniels expõe proposições explicitadas por Leontiev (s/d) e revela a relação entre níveis: no nível mais baixo, encontra-se a operação, a qual acontece de forma automatizada, é executada sem um planejamento prévio e consiste nas rotinas habituais realizadas por um sujeito, relacionadas a uma ação e influenciadas pelas condições gerais da atividade; no outro nível, encontra-se a ação, que consiste num processo consciente, é orientada por objetivos e revela as etapas para a realização da atividade; as ações são planejadas antes de sua execução. Quando uma ação alcança um determinado nível de maturidade e pode ser executada sem um planejamento prévio, passa para o nível de operação. No último estágio, está a atividade, que corresponde às necessidades humanas, sendo orientada ao objeto por um motivo, como também revela a Figura 2.

A formação do engenheiro, como produto de uma atividade em comum, coletiva, no âmbito do ensino, concretiza-se a partir de ações e operações desenvolvidas por diferentes professores. Esse tipo de atividade, com base em Rubtsov (1996), apresenta elementos principais, dos quais, destacam-se: a compreensão mútua da atividade pelos seus participantes (no caso, os diferentes professores envolvidos na formação dos referidos acadêmicos, possibilitando uma relação entre a própria ação individual do professor e o resultado obtido, bem como com as ações de outros professores); a comunicação entre os diferentes professores, assegurando a repartição, a troca e a compreensão mútua; o planejamento das ações individuais pelo professor, levando em conta as ações dos outros professores, com vistas a obter um resultado comum; e a reflexão, pois esta permite ir além dos limites das ações individuais em relação ao esquema geral da atividade proposta, nesse caso, a formação do engenheiro. De acordo com Rubtsov (1996), a reflexão permite o estabelecimento da atitude crítica dos participantes com relação às suas ações, com a finalidade de transformá-las, considerando o seu conteúdo e a forma do trabalho em comum.

O professor está, assim, inserido numa atividade comum, coletiva, cujo produto, no caso considerado, é a formação do engenheiro. Para o professor atender a tal necessidade de formação desse profissional mediante o ensino, os objetivos e ações propostas devem considerar as finalidades do curso, seus objetivos, o perfil do egresso e também o papel da disciplina em que atua. Ressalta-se que a formação do acadêmico não se faz apenas pelo somatório ou pela justaposição de resultados intermediários das atividades/ações/operações dos diferentes sujeitos envolvidos no processo, mas no resultado da atividade coletiva. Nesse contexto, as proposições apresentadas por Rubtsov (1996) mostram-se relevantes no alcance do resultado da formação do engenheiro. 
É cada professor que concretiza os objetivos sociais do currículo apresentado no PPC do(s) curso(s) em questão, a partir de ações. "A atividade humana não pode existir de outra maneira, se não for na forma de ações ou de grupo de ações” (LEONTIEV, 1985, p. 84) [Tradução nossa]. Para Leontiev (1985, s/d), se as ações que constituem a atividade forem retiradas, nada restará da atividade.

Os objetivos não se inventam, não são planejados pelo sujeito a seu arbítrio. Os objetivos estão dados dentro de circunstâncias objetivas. Conjuntamente, a discriminação e concretização dos objetivos são um ato que dista muito de ser automático e monofacetado, sendo que é um processo relativamente prolongado no qual a ação incide sobre os objetivos e donde permite-se à expressão, e se produz à saturação objetal dos mesmos (LEONTIEV, 1985, p. 86). [Tradução nossa]

No ensino de sua disciplina, a partir dos objetivos propostos, os quais precisam concordar com o motivo geral da atividade, o professor, diante de determinadas condições, define ações que possibilitam a concretização de tais objetivos, dentre as quais, destacam-se: estudo do PPC do curso; participação em reuniões de planejamento; elaboração do plano de ensino; compreensão de conceitos específicos da disciplina; relação de aspectos do ensino com pesquisa e extensão e organização das atividades de ensino da disciplina. As ações do professor adquirem significado quando tratadas como parte integrante de uma atividade coletiva, com função determinada para a obtenção de um resultado/produto. Ligadas às ações, estão as operações como formas e métodos de realização de uma ação. O que caracteriza uma operação é sua tecnificação, sua realização automática. Para Leontiev (1985, p. 87), é no “[...] instrumento (um objeto material) que estão presentes os métodos, as operações, mas não as ações nem os objetivos" [Tradução nossa].

A atividade está, assim, vinculada aos motivos e às necessidades e é por eles orientada; as ações, considerando as intencionalidades, são planejadas pelo professor a partir de objetivos, e as operações são desenvolvidas mediante as condições, sejam elas objetivas ou subjetivas.

A formação profissional em nível superior tem um caráter social. Engeström (1987, 1999, 2001, 2002) possibilita a ampliação do entendimento da atividade humana, atendendo à sua natureza como social e coletiva, também considerando as inter-relações entre o sujeito e sua(s) comunidade(s). Engeström $(1987,1999)$ acresce à estrutura da atividade, apresentada por Leontiev, novos componentes, como regra, comunidade e divisão do trabalho, propondo uma forma de representar o caráter social de uma atividade. A Figura 3 adaptada de Engeström (1999), apresenta elementos da atividade e relações entre estes, os quais são entendidos como condição na formação acadêmica do engenheiro. 
Figura 3 - Estrutura de uma atividade que considera seu caráter social e coletivo

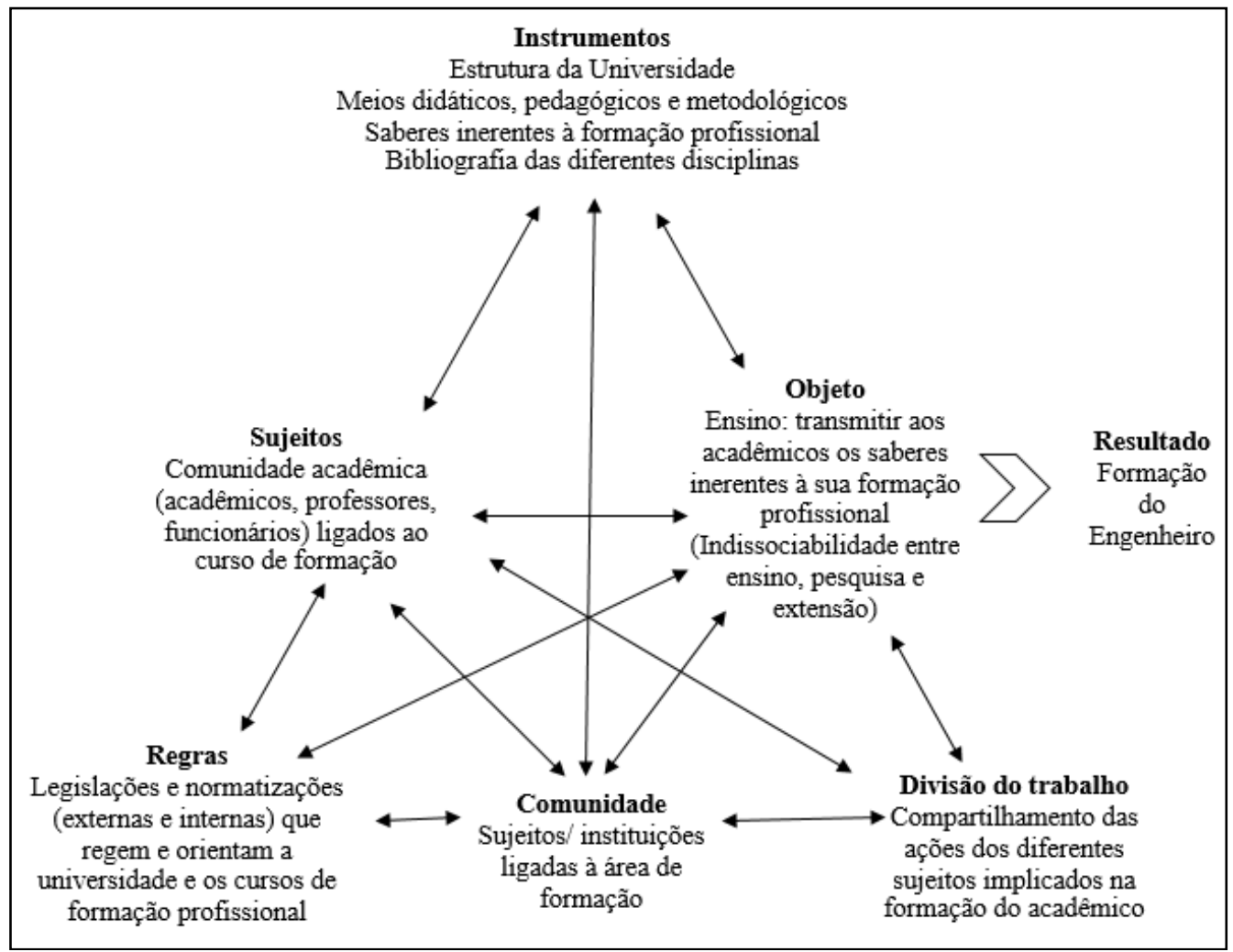

Fonte: Adaptado de Engeström (1999, p. 31)

No sentido exposto, para que o formar um engenheiro se caracterize como uma atividade em comum, coletiva, considerando seu caráter social, o professor, como integrante de uma comunidade, por meio do ensino de conceitos específicos da disciplina que ministra, tem uma necessidade: formar um engenheiro de tal forma que, a partir da objetivação de tal necessidade, motivos sejam criados. Para tanto, entende-se como condição que o professor tenha clareza da importância e da função da disciplina que ministra na formação profissional do acadêmico. Ressalta-se, ainda, que o significado que o objeto "Ensino: transmitir aos acadêmicos os saberes inerentes à sua formação profissional (Indissociabilidade entre ensino, pesquisa e extensão)" tem para cada professor é pessoal e determinante na elaboração dos objetivos e das ações que concretizam a atividade.

\section{Considerações finais}

Visando atender aos objetivos e problemática da investigação - Quais elementos caracterizam a necessidade, o objeto e o motivo como componentes estruturadores da atividade Formação do engenheiro? Quais entendimentos podem ser produzidos, considerando a 
formação do engenheiro, no âmbito do ensino, como produto de uma atividade coletiva? -, apresentamos elementos que sistematizam os argumentos produzidos no decorrer das análises, constituindo, assim, uma síntese da investigação desenvolvida e apresentada no presente texto.

Analisar os cursos a partir de alguns elementos de seus PPCs possibilitou a percepção do professor imerso numa atividade coletiva autêntica que visa à formação de um engenheiro e, assim, a indicação da formação do engenheiro como produto de uma atividade coletiva. É esse produto, segundo o estudo desenvolvido, que estimula a atividade de professores trabalhar junto e que caracteriza a atividade como coletiva.

Análises de elementos dos PPCs dos cursos em questão possibilitaram o entendimento das finalidades destes e a indicação de que tais objetivos se mostram intimamente relacionados ao perfil do egresso apresentado nos referidos documentos. Permitiram, ainda, visualizar o professor inserido numa atividade coletiva que tem como necessidade formar um engenheiro considerando elementos apresentados nos PPCs dos cursos em questão. A clareza da importância e da função da disciplina que o professor ministra mostrou-se como condição da sua inserção na atividade coletiva que tem como necessidade a formação do engenheiro.

O estudo desenvolvido permitiu indicar que essa necessidade se torna satisfeita na atividade coletiva, o que está intrinsecamente relacionado às ações individuais. Nesse sentido, o professor de cada disciplina tem a necessidade de contribuir na formação do engenheiro. Tal necessidade pode ser satisfeita no ensino dos conceitos da disciplina que ministra, o que se configura no objeto da atividade. Esse objeto torna-se o motivo da atividade, aquilo que estimula o professor a colocar-se em atividade, o que possibilita a definição de objetivos que considera o que poderá fazer para satisfazer tal necessidade, e esses objetivos materializam-se nas suas ações.

Os objetivos e as ações propostas pelo professor devem considerar as finalidades do curso, seus objetivos, o perfil do egresso e também o papel da disciplina em que atua.

Entendemos que apresentamos uma abordagem e que em se tratando da formação do engenheiro em nível acadêmico, para além de professores trabalhando em comum, inseridos numa atividade coletiva, há o acadêmico o qual com vistas à sua formação deve também se colocar em atividade, no caso, de aprendizagem. Porém, considerando as delimitações do recorte aqui proposto, indicamos que tais discussões são apresentadas, de forma pontual, em outro momento. 


\section{REFERÊNCIAS}

ARAÚJO, E. S. Da formação e do formar-se: a atividade de aprendizagem docente em uma escola pública. 2003. 173f. Tese (Doutorado em Educação) - Faculdade de Educação da Universidade de São Paulo, São Paulo, 2003.

BATTISTI, I. K. Mediações na significação do conceito vetor com tratamento da geometria analítica em aulas de matemática. 2016. 249f. Tese (Doutorado nas Ciências) Universidade Regional do Noroeste do Estado do Rio Grande do Sul. 2016.

BRASIL. MEC/CNE/CES. Resolução CNE/CES nº 11, de 11 de março de 2002. Diretrizes Curriculares Nacionais do Curso de Graduação em Engenharia. Diário Oficial da União, Brasília, DF, 9 abr. 2002.

CARAÇA, B. de J. Conceitos Fundamentais da matemática. 4. ed. Lisboa: Gradiva, 1998.

DANIELS, H. Vygotsky e a pedagogia. Tradução Milton Camargo Mota. São Paulo: Loyola, 246 p. 2003.

ENGESTRÖM, Y. Learning by expanding: an activity -theoretical approach to developmental research. Helsinki, Finland: Orienta - Konsultit, 1987.

ENGESTRÖM, Y. Activity Theory and Individual and Social Transformation. In: ENGESTRÖM, Y.; MIETTINEN, R.; PUNÄMAKI, R. (ed.) Perspectives on Activity Theory. Cambridge: Cambridge University Press, p. 19-38, 1999.

ENGESTRÖM, Y. Expansive Learning at Work: toward an activity theoretical reconceptualization. Journal of Education and Work, v. 14, n. 1, p. 133-156, 2001.

ENGESTRÖM, Y. Non scolae sed vitae discimus: Como superar a encapsulação da aprendizagem escolar. In: DANIELS, H. Uma Introdução a Vygotsky. São Paulo: Edições Loyola, 2002. p. 175-197.

GARNIER, C; BEDNARZ, N; ULANOVSKAYA, I. Duas diferentes visões da pesquisa em Didática. In: Após Vygotsky e Piaget: perspectiva social e construção escolar russa e ocidental. Porto Alegre: Artes Médicas, 1996.

LEONTIEV, A. N. Activity and Consciousness. Englewood Cliffs, Prentice-Hall,1977.

LEONTIEV, A. N. Actividad, conciencia e personalidad. Havana: Editorial Pueblo y Educación. Traducción: Lic. Librada Leyva Rosario Bilbao Jorge C. Potrony. Revisión técnica: Lic. Franklin Martínez, 1985.

LEONTIEV, A. N. O desenvolvimento do psiquismo. Lisboa: Horizonte Universitário, s/d.

KOPNIN, P. A dialética como lógica e teoria do conhecimento. Rio de Janeiro: Civilização Brasileira, 1978. 
MOURA, M. O. de. O educador matemático na coletividade de formação: uma experiência com a escola pública. Tese (Livre Docência) — Faculdade de Educação, Universidade de São Paulo, São Paulo, SP. 2000.

MOURA, M. O. de. Pesquisa colaborativa: um foco na ação formadora. In: BARBOSA, Raquel Lazzari Leite (Org.) Trajetórias e perspectivas da formação de educadores. São Paulo: Editora UNESP, 2004. p. 257-284.

MOURA, M. O. de.; SFORNI, M. S. de F.; ARAÚJO, E. S. Objetivação e Apropriação de Conhecimentos na Atividade Orientadora de Ensino. Revista Teoria e Prática da Educação, v. 14, n. 1, p. 39-50, jan./abr. 2011. Disponível em:

www.dtp.uem.br/rtpe/volumes/v14n1/04.pdf. Acesso em: 10 maio 2012.

OLIVEIRA, M. K. Vygotsky: aprendizado e desenvolvimento - um processo sócio- histórico. 4. São Paulo: Editora Scipione. 2004.

RUBTSOV, V. A atividade de aprendizado e os problemas referentes à formação do pensamento teórico dos escolares. In: GARNIER, C. et al. (Org.). Após Vygotsky e Piaget: perspectivas social e construtivista escolas russa e ocidental. Porto Alegre: Artes Médicas, 1996.

VIGOTSKI, L. V. A Construção do pensamento e da linguagem. Tradução de Paulo Bezerra. São Paulo: Martins Fontes, 2001.

SACRISTÁN, J. G. Consciência e a ação sobre a prática como libertação profissional dos professores. In: NÓVOA, A. N. (Org.) Profissão Professor. Portugal: Porto Editora, 1991.

\section{Como referenciar este artigo}

BATTISTI, Isabel Koltermann; NEHRING, Cátia Maria. A formação acadêmica do engenheiro: produto de uma atividade coletiva. Revista Ibero-Americana de Estudos em Educação, Araraquara, v. 14, n. 2, p. 543-558, abr./jun., 2019. E-ISSN: 1982-5587. DOI: 10.21723/riaee.v14i2.11434

Submetido em: 06/06/2018

Aprovado em: 30/10/2018 